\title{
La Ley aplicable al Contrato de Franquicia Internacional en la Unión Europea
}

\author{
William Fernando Martínez, Luna \\ Doctor en Derecho de la Universidad Carlos III de Madrid. Máster en Derecho Privado de la Universidad Carlos III, \\ Madrid. Máster en Derecho de los Negocios y Litigación Internacional, Universidad Rey Juan Carlos de Madrid. \\ Abogado de la Universidad Santo Tomás de Bucaramanga (Colombia) Docente completo de la \\ Universidad Jorge Tadeo Lozano (Colombia)E-mail: williamf.martinezl@utadeo.edu.co
}

\section{Resumen}

La ley aplicable a los contratos internacionales de franquicia en ausencia de elección de parte en la Unión Europea, estuvo regulada durante muchos años por el Artículo 4 del Convenio de Roma de 1980. Dicho Artículo requería establecer la parte que realizaba la prestación característica de la relación contractual, para que la ley de su residencia habitual regulara el contrato. La aplicación judicial de este precepto presentó graves inconvenientes en la determinación de la ley aplicable al contrato de franquicia, pues no existió unanimidad acerca de la parte que llevaba a cabo dicha prestación, e incluso se discutía si dicho contrato tenía un prestador característico. Con la transformación del Convenio de Roma en un Reglamento de la Unión Europea (Roma I) se aprovechó para hacer importantes cambios al Artículo 4, donde cobra especial importancia la regulación rígida establecida para el contrato de franquicia. El presente Artículo pretende analizar si dichos cambios pueden solucionar los problemas presentados en el Convenio de Roma y brindar seguridad jurídica mediante la previsibilidad del derecho aplicable a los contratos internacionales de franquicia

Palabras clave: Contratos internacionales, Franquicia, Ley aplicable, Convenio de Roma de 1980, Reglamento Roma I.

\begin{abstract}
Article 4 of the Rome Convention of 1980 governed the applicable law in absence of choice to international franchise contracts in the European Union, for many years. This article needed to establish the characteristic performance of the contractual relationship, because the law of habitual residence regulates the contract. Judicial enforcement of this provision presented serious difficulties in determining the law applicable to the franchise agreement because there was no unanimity on the part carrying out this provision, even was discussed if the contract had a characteristic performer. With the conversion of the Rome Convention into a Regulation of the European Union (Rome I) was used to make important changes to Article 4, where is particularly important the rigid norm for the franchise agreement. This article aims to analyze whether such changes may solve the problems presented in the Rome Convention and provide legal certainty by the predictability of the law applicable to international franchise contracts.
\end{abstract}

Keywords: International contact, Franchise, Applicable law, Rome Convention, Rome I Regulation.

\section{Résumé}

La loi applicable aux contrats internationaux de franchise en l'absence de choix des parties à l'Union européenne, a été réglementée depuis de nombreuses années à l'article 4 de la Convention de Rome de 1980. Article Saïd nécessaire pour établir la partie exécutante la prestation caractéristique de la relation contrat, que la loi de sa résidence habituelle à réguler le marché. L'exécution judiciaire de cette disposition avait de sérieux inconvénients dans la détermination de la loi applicable au contrat de franchise parce qu'il n'y avait pas d'unanimité sur la partie mise en oeuvre de cette disposition, même si le contrat a été discuté avait un fournisseur distinct. Avec la transformation de la Convention de Rome en un règlement de l'Union européenne (Rome I) a été utilisé pour rapporter des changements majeurs à l'article 4, dans lequel les réglementations rigides établis pour le contrat de franchise est particulièrement important. Cet article vise à analyser si ces changements peuvent résoudre les problèmes posés dans la Convention de Rome et assurer la sécurité juridique par la prévisibilité de la loi applicable aux contrats internationaux de franchise.

Mots-clés: Les contrats internationaux, La franchise, La loi applicable, La Convention de Rome de 1980, Règlement Rome I 



\section{La Ley aplicable al Contrato de Franquicia Internacional en la Unión Europea*}

William Fernando Martínez Luna

\section{INTRODUCCIÓN}

La franquicia representa a día de hoy uno de los más importantes sistemas de expansión empresarial de la economía moderna, es una nueva e innovadora forma de colaboración empresarial que pretende escapar del monopolio impuesto por las grandes compañías trasnacionales ${ }^{1}$. Para contrarrestarlo, las pequeñas y medianas empresas se han organizado por medio de acuerdos comerciales, procurando alcanzar una mayor porción del mercado al menor coste posible y trayendo beneficios para todos los intervinientes. La franquicia forma parte de la denominada distribución comercial, la cual es considerada como una etapa destacada del proceso económico, ubicada entre el suministro de servicios o la fabricación de los bienes y su uso o consumo por parte del consumidor final (Pellisé de Urquiza, 1999, p. 21).

El modelo de colaboración empresarial desarrollado mediante la franquicia, se constituye en una inmejorable vía de crecimiento para aquellas empresas que pretendan expandir su mercado de manera rápida, al menor coste posible, $\mathrm{y}$ manteniendo el control del proceso de distribución (Baena, 2009, p. 44).

De la misma forma, la franquicia permite el ingreso de nuevos competidores al mercado, genera una mayor competencia entre las diferentes marcas y propicia una mayor diversidad de opciones al consumidor final (García 2000, p.114).

Aunque en sus orígenes la franquicia se desarrolló únicamente en los mercados nacionales, hoy en día ostenta una elevada proyección hacia el mercado extranjero (Fuentes, 2001, p. 118). Es importante destacar que aunque los contratos de franquicia tienen una gran presencia en la distribución internacional de bienes, en los últimos años se ha constituido en la más importante vía de la distribución comercial de los servicios (Pellisé De Urquiza, 1999, p. 24).

* $\quad$ El presente artículo hace parte de la investigación: La ley aplicable a los contratos internacionales en la Unión Europea. Departamento de Derecho Internacional Privado. Universidad Carlos III Madrid. Doctorado en Derecho.

$1 \quad$ STS de 27 septiembre 1996 RJ $1996 \backslash 6646$. 
Justamente esta vocación internacional de la franquicia se ha venido convirtiendo en uno de los rasgos más característicos de esta relación empresarial, es por eso que el Derecho internacional privado ha venido prestando especial atención a esta figura jurídica novedosa y de gran impacto en el actual momento económico y comercial globalizado.

En efecto, cuando un empresario cuenta con un modelo de negocio exitoso y pretende incursionar en el mercado extranjero, debe asumir importantes incertidumbres legales que van a incidir directamente en los costes de la operación. En primer lugar, debe establecer cuál será el juez competente en caso de presentarse un conflicto jurídico, en segundo lugar, debe determinar bajo cuál norma jurídica nacional se resolverá dicha disputa, y finalmente, si la sentencia proferida podrá ser ejecutada en el país de su interés. Por tal motivo, el principal problema que debe enfrentar el empresario que quiera comercializar sus productos en el extranjero, es asumir el riesgo de litigar por fuera de sus fronteras. Este riesgo de litigar a nivel internacional se encuentra forzosamente ligado a esta clase de relaciones comerciales, es oneroso y perjudicial, pues adhiere costos a la transacción (Fentiman, 2010, p. 3); es lo que la doctrina ha calificado como el "coste internacional de Derecho Internacional Privado" (Carrascosa, 2004, p. 38).

Por lo anterior, las normas jurídicas que regulan el intercambio comercial internacional adquieren hoy más que nunca una importancia mayúscula, pues se hace necesario otorgar la idónea protección a los intervinientes en las transacciones jurídicas trasnacionales.

El tema de la ley aplicable a los contratos internacionales ha venido teniendo importantes avances no solamente de orden legislativo nacional y en Convenios internacionales (ad. ex. Convención de Viena sobre compra venta internacional de mercaderías), sino desde los propios participantes del comercio internacional, creando disposiciones al margen de los Estados que pretenden regular de manera uniforme los distintos contratos trasnacionales, es el caso de los Principios de UNIDROIT.

La Unión Europea ha considerado vital para el correcto funcionamiento del mercado interior, disponer de normas jurídicas que permitan prever a las partes del contrato, con alto grado de certeza, cuál ley será aplicable para resolver su conflicto jurídico internacional. La solución más idónea sería contar con normas materiales uniformes para todos los países de la Unión Europea, pues de esta manera se eliminaría el conflicto de leyes. Sin embargo, a día de hoy no se cuenta con una regulación material uniforme en materia de contratos que permita solucionar todos los conflictos jurídicos que se presenten en el plano internacional. Por tal motivo, la Unión Europea ha entendido que para otorgar seguridad jurídica a los contratantes mediante la previsibilidad de la ley aplicable a su negocio jurídico internacional, se deben unificar las normas de conflicto $^{2}$, para que de esta forma, el juez del Estado miembro que conozca de un conflicto jurídico contractual, pueda determinar la ley

2 Es necesario precisar que las normas de conflicto no dan solución directa y material al problema jurídico presentado en un contrato internacional, su labor es determinar cuál ley nacional regulará dicha relación jurídica. 
aplicable utilizando la misma norma jurídica que utilizaría cualquier juez de la Unión Europea. Así, los contratantes podrán conocer ex ante basados en dicha norma de conflicto uniforme la ley que regulará su contrato internacional y podrán adaptar su conducta comercial a una ley previamente conocida por ellas.

Esta norma de conflicto uniforme no regula exclusivamente relaciones jurídicas entre personas o empresas domiciliadas en países de la Unión Europea, pues su carácter universal permite ser utilizada sin importar la nacionalidad de las partes, la residencia o domicilio de los contratantes, es decir, tan solo basta que el proceso jurídico lo conozca cualquier juez de los países de la Unión Europea, para que sea utilizada dicha norma de conflicto para determinar la ley aplicable al contrato. De esta manera, el cuerpo jurídico uniforme puede perfectamente regular un contrato de franquicia entre una empresa con domicilio en Colombia y otra con domicilio en Francia, cuando las normas de competencia judicial internacional determinen que el juez de conocimiento es un juez de la Unión Europea. Esta circunstancia es vital para los empresarios Colombianos, mucho más ahora que se ha firmado un Tratado de Libre Comercio con la Unión Europea, pues para cualquier disputa presentada en su contrato, y que sea competente un juez de la Unión Europea, deberá establecerse la ley aplicable utilizando las disposiciones uniformes de la unión Europea.

La ley aplicable a los contratos internacionales en la Unión Europea ha estado regulada por dos cuerpos jurídicos uniformes: el Convenio de Roma de 1980 y el Reglamento Roma I. El Convenio de Roma de 1980 reguló el tema de la ley aplicable a los contratos internacionales en la Unión Europea durante más de veinte años, sin embargo, y a pesar de su innegable contribución en la solución del conflicto de leyes, se hacía necesaria su transformación en un instrumento jurídico propio de la Unión Europea, en este caso un Reglamento, pues era la única norma jurídica de Derecho internacional privado de la Unión Europea que aún conservaba la forma de Convenio internacional, lo que conllevaba enormes problemas de tipo formal, ad. ex., dificulta a la hora de modificar su clausulado, pues requería la aprobación de todos los Estados parte, o cuando un nuevo país ingresaba a la Unión Europea, el Convenio de Roma sólo entraría en vigor para ese país después de la ratificación del Convenio por parte del respectivo parlamento, lo que producía demoras injustificadas.

El Reglamento Roma I reemplazó al Convenio de Roma de 1980 a partir del 17 de diciembre de 2009, lo anterior significa que los contratos celebrados a partir de esa fecha quedan regulados exclusivamente por el Reglamento Roma I. Durante el proceso de transformación del Convenio de Roma de 1980, los Estados parte establecieron que era necesario hacer algunos cambios al clausulado del Convenio; por un lado, para solucionar los distintos problemas presentados en su aplicación, y por otro, para actualizar sus disposiciones al comercio internacional globalizado.

El Artículo 4 del Convenio de Roma de 1980 regulaba la ley aplicable al contrato internacional cuando las partes no habían hecho una válida elección de ley. Dicho precepto presentó innumerables problemas a la hora de establecer la ley aplicable al contrato de franquicia, lo que provocó sentencias contradictorias en las distintas 
Cortes de los Estados parte. El nuevo Reglamento Roma I ha hecho importantes modificaciones al Art. 4 para evitar los problemas de interpretación del Convenio de Roma de 1980 y ha prestado especial atención al contrato de franquicia estableciéndole de manera rígida la ley aplicable: la ley aplicable al contrato de franquicia será la de la residencia habitual del franquiciado.

El presente Artículo pretende analizar los cambios introducidos en el Art. 4 Reglamento Roma I respecto del contrato de franquicia, para establecer si con la determinación de la ley aplicable de manera rígida y directa a esta relación jurídica internacional, se logra solucionar los problemas presentados bajo la aplicación del Convenio de Roma de 1980, y de esta manera, garantizar la seguridad jurídica al contratante internacional. El estudio partirá de una precisión conceptual del contrato de franquicia, para posteriormente abordar el tema conflictual que iniciará con el estudio del Convenio de Roma de 1980, para finalmente profundizar en los importantes cambios realizados al Reglamento Roma I.

\section{PRECISIONES CONCEPTUALES DEL CONTRATO DE FRANQUICIA INTERNACIONAL}

El contrato de franquicia es uno de los contratos atípicos que más ha sido estudiado por la doctrina especializada. No obstante, su definición también la podemos hallar en la propia norma jurídica y en la jurisprudencia.

El Reglamento núm. 4087/88 de la Comisión, de 30 de noviembre de 1988, relativo a la aplicación del apartado 3 del Artículo 85 del tratado a categorías de acuerdos de franquicia, define el contrato de franquicia en los siguientes términos: "el contrato en virtud del cual una empresa, el franquiciador, cede a la otra, el franquiciado, a cambio de una contraprestación financiera directa o indirecta, el Derecho a la explotación de una franquicia para comercializar determinados tipos de productos y/o servicios y que comprende por lo menos:

- $\quad$ El uso de una denominación o rótulo común y una presentación uniforme de los locales y/o de los medios de transporte objeto del contrato,

- $\quad$ La comunicación por el franquiciador al franquiciado de un « know-how », y la prestación continua por el franquiciador al franquiciado de asistencia comercial o técnica durante la vigencia del acuerdo [...]."

Asimismo, la jurisprudencia la ha definido como una modalidad contractual donde:

Una de las partes que es titular de una determinada marca, rótulo, patente, emblema, fórmula, método o técnica de fabricación o actividad industrial o comercial, otorga a la otra el Derecho a utilizar, por un tiempo determinado y en una zona geográfica delimitada, bajo ciertas condiciones de control, aquello sobre lo que ostentaba la titularidad, contra la entrega de una 
prestación económica, que suele articularse normalmente mediante la fijación de un canon o porcentaje (STS Civil, 4 de marzo, 1997).

La doctrina por su parte entiende que es:

Aquel contrato de distribución comercial en el que el concedente (franquiciador) cede al cesionario (franquiciado) un método empresarial propio y completo a través de la transmisión de sus elementos distintivos (marcas, rótulos, imagen corporativa), un saber hacer (know-how), suministros y asistencia técnica (formación profesional continua, asesorías varias etc.) y todo ello a cambio de una contraprestación económica directa o indirecta" (Burgos, 2010, p. 214) . $^{3}$

De acuerdo a estas definiciones, se puede extraer la esencia misma del contrato de franquicia, que no es otro que la reproducción de un modelo de empresa, pues en definitiva, lo que busca el franquiciado es la "reiteración de un éxito comercial" (García, 2010, p. 250).Teniendo en cuenta lo anterior, se pueden descubrir sus caracteres básicos.

La franquicia es un contrato celebrado por empresarios independientes que se unen para formar una red de colaboración empresarial. Aunque es claro que los empresarios que forman parte de la franquicia son jurídica y económicamente independientes, también lo es que se encuentran fuertemente vinculados a nivel operativo (Pellisé de Urquiza, 1999, p. 41).

En la franquicia un empresario que cuenta con una experiencia previa en un determinado mercado y que goza de un nivel de prestigio, realiza la "cesión" de un conjunto de bienes inmateriales y materiales perfectamente organizados, que conforman el modelo empresarial de la empresa franquiciante (Mayorga, 2007, p. 7). Este grupo de bienes inmateriales transmitidos por el franquiciador, está conformado por los signos distintivos de la empresa, y todo el conjunto de conocimientos, métodos y procesos que componen el know-how. La transmisión del knowhow, constituye el elemento que da la esencia al contrato de franquicia, el cual es definido como "un

$3 \quad$ Otras interesantes definiciones del contrato de franquicia son: "Es una técnica de colaboración empresarial mediante la cual una empresa (franquiciador) que ha ideado y experimentado un producto, un servicio, o un particular proceso productivo o distributivo, concede a terceros empresarios independientes (Franquiciados), la autorización para producir y vender, para vender o para prestar servicios, bajo los signos distintivos y con las modalidades o técnicas de comercialización del concedente", (Domínguez, 2004, p.494), asimismo, se considera que es un "acuerdo por el cual una empresa (franquiciador) cede a otras (franquiciados) el derecho de explotación de la franquicia, entendiéndose por ésta el conjunto de derechos sobre una marca, nombre rótulo de establecimiento, diseño, know-how o patente incorporados y explotables comercialmente con un producto o servicio", (Besco, s.f., p.75) el contrato de franquicia es un "contrato completo y atípico, consensual y sinalagmático, civil o mercantil según su objeto, mediante el cual una de las partes, el concedente o el franquiciador, concede a otra, denominada, concesionario o franquiciado, mediante el pago de un canon, el derecho a explotar una marca, una fórmula comercial privativa, o un servicio con prestaciones accesorias, previamente convenidas”. (Chulia y Beltrán, 1992, p. 164). 
conjunto de conocimientos prácticos no patentados derivados de la experiencia del franquiciador y verificados por éste, que es secreto, sustancial e identificado"(Duran, 2006, p. 429). Por tal motivo, la explotación de estos Derechos de "propiedad industrial y know-how" juegan un rol vital en los contratos de franquicia (De Miguel, 2000. p. 86). También es importante destacar, que junto a la transmisión del Know-how, es común que se acompañe el licenciamiento de Derechos de propiedad intelectual.

En el contrato de franquicia también puede darse la transmisión de bienes materiales. Estos bienes le permiten al franquiciado llevar a cabo su actividad comercial con éxito, ya que van desde la propia maquinaria para fabricar los bienes o prestar los servicios, los medios de transporte, el propio mobiliario, hasta el suministro de los productos a comercializar (García 2010, p. 251). Este modelo de negocio transmitido por el franquiciador es explotado por el franquiciado bajo su responsabilidad. Sin embargo, y a pesar de que el franquiciado es una empresa totalmente autónoma, el franquiciador se reserva contractualmente el derecho de supervisión y control de toda la red de franquicia. Este aspecto es de vital importancia, ya que con él se mantiene la uniformidad del negocio y se evita un posible deterioro de la marca (Mayorga, 2007, p. 8).

En suma, el contrato de franquicia tiene como objetivo la "difusión" de productos o servicios en un mercado concreto, donde las dos partes de dicho contrato son empresarios independientes, que deben asumir por separado la responsabilidad ante terceros que les impone su propia actividad empresarial (Duran, 2006, p.426).

Todos estos rasgos que caracterizan el contrato de franquicia, se pueden ver modificados o en su caso afianzados si se está en presencia de una franquicia internacional. Y esto porque la franquicia internacional le impone a los contratantes un entorno totalmente diferente al de una franquicia interna, no sólo desde el punto de vista económico, que si bien es cierto constituye un aspecto de vital importancia a la hora de acceder a un mercado extranjero, sino también desde el punto de vista cultural y sobre todo el legal (Fuentes, 2001, p.124).

En efecto, la contratación internacional de una franquicia necesita una especial adaptación de su objeto a un escenario trasnacional, requiriendo la inclusión de aspectos contractuales que no se contemplan en las relaciones internas, o el establecimiento de una protección concreta para ciertos elementos del contrato, ad ex., la marca y signos distintivos, duración del contrato, la concreción del determinado territorio para operar etc.

Un aspecto vital del contrato internacional de franquicia y que no está presente en una franquicia interna, es el referente a la resolución de conflictos. Los contratantes deben incorporar a las negociaciones los aspectos referentes a la inclusión de una cláusula de elección de tribunal, o de sumisión al arbitraje internacional, así como una cláusula de elección de la Ley que regulará su relación jurídica (Fuentes, 2001, p. 125). 


\subsection{Ventajas de la Franquicia}

La franquicia constituye un proceso de expansión de una empresa mediante la transmisión de un modelo de negocio, con amplias ventajas para las partes intervinientes. Prueba de ello es el elevado crecimiento de esta figura empresarial en los últimos años, y la baja tasa de fracasos comerciales con respecto a otras figuras de colaboración empresarial (García, 2010, p. 257).

Se pueden encontrar entonces las siguientes ventajas para el franquiciador. Un empresario que cuenta con negocio líder en su sector comercial, normalmente toma la decisión de franquiciarlo cuando no cuenta con los recursos financieros suficientes para propiciar el crecimiento independiente de su empresa. Otro factor que influye en esta decisión, es el hecho de ganarles, de forma rápida y eficiente, el terreno a sus competidores directos. Pues bien, estas dos principales razones para franquiciar un negocio se constituye en las primeras ventajas del franquiciador, esto es, conseguir la ocupación rápida de un mercado concreto, evitando que la competencia le gane terreno en dicho sector del mercado (Burgos y Fernández, 2010, p. 64). Otra ventaja, por supuesto, es el incremento económico. El franquiciador tendrá un crecimiento empresarial sin la necesidad de aumentar sus costes de operación, toda vez que contará con más "unidades franquiciadas" operando en el mercado. De la misma forma, obtendrá una mayor ventaja de negociación por volumen de producto con sus proveedores.

"Con la franquicia, el empresario franquiciador consigue desplazar los riesgos y los costes de la operación a otra empresa" (Domínguez, 2004, p. 494). Esta circunstancia es de vital importancia, puesto que el franquiciador desplaza la responsabilidad laboral de su fuerza de trabajo a un tercero, siendo ésta una carga importante para cualquier empresario (Burgos y Fernández, 2010, p. 64). Adicionalmente, "el franquiciador permanece con el control de la explotación de forma descentralizada" (Domínguez, 2004, p. 494). De la misma manera, con la franquicia, el empresario franquiciador consigue una disminución importante en los costes de índole publicitario, puesto que éste rubro será también cubierto por todas las empresas franquiciadas (Burgos y Fernández, 2010, p. 64).

En suma, este sistema de colaboración empresarial permite que el franquiciante consiga el fortalecimiento de su marca comercial, al obtener un alto nivel de penetración en el mercado (Guillen, 1995, citado en Martínez, 2012, p. 283).

Por su parte se pueden resumir las ventajas del franquiciado de la siguiente manera: la principal ventaja que obtiene el franquiciado cuando se introduce en esta forma de negocio, es la "transmisión de conocimientos" por parte del franquiciador. Estos conocimientos son de diversa índole, pero todos ellos de gran trascendencia a la hora de emprender la labor comercial. Van desde la experiencia misma del desarrollo del negocio, es decir, toda la información correspondiente a los aciertos y errores en el día a día de la operación, hasta toda la información vital que identifica e individualiza el negocio franquiciado (Burgos y Fernández, 2010, p. 64). Otra ventaja 
indiscutible, radica en que el franquiciado adquiere la participación en la reputación de una empresa previamente consolidada en un sector comercial, y adicionalmente, se beneficia de unas técnicas de comercialización y de gestión previamente contrastadas(Domínguez, 2004, p. 494). Esto le permite al comerciante franquiciado, no solamente establecer su negocio más rápidamente, sino que las probabilidades de éxito son mucho mayores de las que tendría sin la experiencia transmitida por el franquiciador (Guardiona, 1998, p. 252). A pesar de que su inversión inicial puede llegar a ser de un monto importante, indudablemente es mucho menor de la que hubiese tenido que asumir, si constituye un negocio independiente de rasgos similares. Sin duda, el establecimiento de un territorio único y reservado donde opere la franquicia, constituye otra de sus principales ventajas. En todos los sectores comerciales existe una alta competencia por el consumidor final, es por eso, que el hecho de explotar un negocio, incluida su marca comercial reconocida en un determinado territorio, favorecerá directamente al franquiciado. (Domínguez, 2004, p. 494). Por último, la reputación y la experiencia del franquiciante hacen más fácil que el franquiciado incorpore nuevos clientes, puesto que muchos de ellos ya mantienen una fidelidad con la marca del producto o servicio (Guillen, 1995, Citado en Martínez, 2012, p. 284).

\subsection{Obligaciones de las partes}

"El contrato de franquicia es tal vez el contrato atípico que más obligaciones conlleva para las partes intervinientes" (Mayorga, 2007, p. 101). Dichas obligaciones lo diferencian de otros contratos de colaboración que cuentan con características similares, cuestión de gran importancia a la hora de establecer su Ley aplicable, puesto que en muchos casos las partes creen haber celebrado una figura contractual específica, pero la realidad obligacional demuestra que ha sido otra, y como el Reglamento Roma I establece ahora disposiciones rígidas para ciertos contratos del comercio internacional, la calificación de dichas relaciones jurídicas cobra ahora mucha importancia. Asimismo, las obligaciones llevadas a cabo por los contratantes en el contrato de franquicia, demuestra que existe un equilibrio entre las partes, situación ésta, que dificultó enormemente la designación de la Ley aplicable, mediante la identificación de la parte que llevaba a cabo la prestación característica del contrato.

Por lo anterior, es pertinente abordar el estudio de las diferentes obligaciones que cumplen las partes al interior de este contrato. Antes de comenzar, es importante destacar que la multiplicidad de tipos de franquicia encontradas en el tráfico comercial, conlleva la existencia de una multiplicidad de obligaciones, cada una de ellas de acuerdo al objetivo buscado por las partes. No obstante, existen ciertas obligaciones que caracterizan el tipo contractual, y que pueden resumirse de la siguiente manera: 


\subsubsection{Obligaciones del franquiciador.}

La principal obligación del franquiciador es, sin duda, la transmisión del "modelo de empresa" que va a adelantar el franquiciado. Sin embargo, para que esta obligación sea cumplida, se hace necesario que el negocio franquiciado haya sido previamente experimentado y probado con éxito al interior del mercado (Mayorga, 2007, p. 105). La obligación de entrega o transmisión del modelo de empresa, incluye el uso de un rótulo, signos distintivos, y la transmisión del Know-how. Esta transmisión de los conocimientos empresariales conocido como el Know-how se constituye en el elemento básico del contrato de franquicia, y que sin él, este sistema de distribución comercial no podría funcionar de manera adecuada (Vega, 1988, p. 326).

De igual manera, el franquiciador tiene que llevar a cabo unas obligaciones anexas a la transmisión del modelo de negocio, tales como, otorgar asistencia técnica, comercial, y en definitiva, toda la asesoría necesaria para que su modelo de negocio pueda ser desarrollado exitosamente por el franquiciado (Jiménez, 2010. p. 399). Debe garantizar el derecho a explotar la franquicia en una determinada zona y por el tiempo establecido en el contrato. Cuando el tipo de franquicia lo requiera, el franquiciador debe proveer las mercancías al franquiciado para que éste proceda a la explotación de su modelo de franquicia (Duran, 2006, p. 430). Debe a su vez:

- $\quad$ Diseñar, desarrollar y costear las estrategias publicitarias para difundir la marca y el rótulo del negocio franquiciado (STS, 27 septiembre, 1996 RJ 1996\6646; Jiménez, 2010. p. 399).

- Adelantar las labores de supervisión y control del uso de las diferentes técnicas comerciales, con el fin de preservar un alto grado de calidad de los productos o servicios, que le permita conservar su reputación comercial (Angulo, 2009, p. 287).

- Y adoptar todas aquellas medidas necesarias para la protección del prestigio, y la identidad de la red comercial de franquicias que se representan por su propio rótulo (STJCE 1986\34).

\subsubsection{Obligaciones del franquiciado.}

La principal obligación del franquiciado es la obligación de pago en los términos establecidos en el contrato. Éste consiste habitualmente en un abono inicial que se entrega con la firma del contrato, y pagos sucesivos de acuerdo a los porcentajes, periodos y criterios acordados por las partes (Duran, 2006, p. 429). Otra obligación no menos importante, es la explotación de forma autónoma del negocio concedido, ya sea comercializando las mercancías, fabricándolas y comercializándolas, o prestando los servicios que son objeto del contrato (Domínguez, 2006, p. 429).

Asimismo, debe el franquiciado emplear las técnicas comerciales transmitidas por el franquiciador, respetando siempre su imagen corporativa (Angulo, 2009, p. 
287). Mantener informado al franquiciador en los términos acordados, de todos los aspectos inherentes al desarrollo del negocio; tiene además el franquiciado la obligación de confidencialidad, que abarca no sólo el tiempo de duración del contrato, sino con posterioridad a él, no pudiendo revelar los secretos inherentes a la relación comercial; tiene la obligación de sometimiento a las instrucciones del franquiciador, especialmente aquellas referentes a los precios, así como su control e inspección(Domínguez, 2004, p. 556). Mantener una idónea cantidad de productos o de medios para el correcto funcionamiento del negocio franquiciado (Jiménez, 2010. p. 400). Y cumplir fielmente los pactos de exclusividad establecidos (Angulo, 2009, p. 287).

\section{LA LEY APLICABLE AL CONTRATO INTERNACIONAL DE FRANQUICIA BAJO EL CONVENIO DE ROMA DE 1980}

El Artículo 4 del Convenio de Roma determinaba la ley aplicable al contrato en defecto de elección de parte utilizando el principio de los vínculos más estrechos ${ }^{4}$. Dicho principio buscaba que la ley del país más próximo y más vinculado con el contrato gobernara la relación jurídica internacional. Sin embargo, como el principio de los vínculos más estrechos era de difícil concreción al caso particular, el Art. 4 Convenio de Roma incluyó una presunción que buscaba precisamente concretar dicho principio, dotando de cierta rigidez la elección de la ley aplicable. De esta manera, el Art. 4 Convenio de Roma presumía que el contrato tenía los vínculos más estrechos

$4 \quad$ El Artículo 4 del Convenio de Roma establece lo siguiente: 1. En la medida en que la ley aplicable al contrato no hubiera sido elegida conforme a las disposiciones del Artículo 3, el contrato se regirá por la ley del país con el que presente los vínculos más estrechos. No obstante, si una parte del contrato fuera separable del resto del contrato y presenta una vinculación más estrecha con otro país, podrá aplicarse, con carácter excepcional, a esta parte del contrato la ley de este otro país. 2. Sin perjuicio del apartado 5, se presumirá que el contrato presenta los vínculos más estrechos con el país en que la parte que deba realizar la prestación característica tenga, en el momento de la celebración del contrato, su residencia habitual o, si se tratare de una sociedad, asociación o persona jurídica, su administración central. No obstante, si el contrato se celebrare en el ejercicio de la actividad profesional de esta parte, este país será aquel en que esté situado su establecimiento principal o si, según el contrato, la prestación tuviera que ser realizada por un establecimiento distinto del establecimiento principal, aquel en que esté situado este otro establecimiento. 3. No obstante lo dispuesto en el apartado 2, en la medida en que el contrato tenga por objeto un derecho real inmobiliario o un derecho de utilización de un inmueble, se presumirá que el contrato presenta los vínculos más estrechos con el país en que estuviera situado el inmueble. 4. El contrato de transporte de mercancías no estará sometido a la presunción del apartado 2. En este contrato, si el país en el que el transportista tiene su establecimiento principal en el momento de la celebración del contrato fuere también aquel en que esté situado el lugar de carga o de descarga o el establecimiento principal del expedidor, se presumirá que el contrato tiene sus vínculos más estrechos con este país. Para la aplicación del presente apartado, se considerarán como contratos de transporte de mercancías los contratos de fletamento para un sólo viaje u otros contratos cuyo objeto principal sea el de realizar un transporte de mercancías. 5. No se aplicará el apartado 2 cuando no pueda determinarse la prestación característica. Las presunciones de los apartados 2, 3 y 4 quedan excluidas cuando resulte del conjunto de circunstancias que el contrato presenta vínculos más estrechos con otro país. 
con el país donde la parte que debía realizar la prestación característica tuviera su residencia habitual. Por lo tanto, el juez a la hora de establecer la ley aplicable al contrato mediante el Art. 4 Convenio de Roma, debía en primer lugar identificar la prestación característica del contrato en cuestión, posteriormente, establecer la parte encargada de efectuar dicha prestación, y finalmente, comprobar el país de la residencia habitual del prestador característico para que su ley gobernara el contrato.

La aplicación judicial de este precepto no tuvo especial dificultad en contratos donde existía un intercambio simple de cosas o servicios por dinero, como en la compraventa de mercaderías, pues era fácil establecer que la obligación no dineraria era la que caracterizaba el contrato, en este caso el prestador característico era el vendedor. No obstante, muchos de los contratos internacionales no cumplen con este intercambio simple de cosas o servicios por dinero, sino que presentan un entramado de prestaciones recíprocas entre las partes, situación que dificultó la determinación del prestador característico como paso previo para establecer la ley aplicable al contrato internacional mediante el Convenio de Roma.

Las características propias del contrato de franquicia, permiten entender la dificultad que presentó en el Convenio de Roma de 1980 la designación de su Ley aplicable (García, 2008, p. 234). Las particularidades de esta figura contractual, unida a las diversas y complejas obligaciones llevadas a cabo por los contratantes, fueron un obstáculo para la correcta aplicación del Art. 4 Convenio de Roma de 1980, pues teniendo en cuenta que el Art. 4.2. Convenio de Roma de 1980 requería descubrir el prestador característico de la obligación, indudablemente dicha tarea poseía una alta complejidad en este contrato.

Por lo tanto, el principal problema para la designación de la Ley aplicable al contrato de franquicia en ausencia de elección de parte, lo constituyó sin lugar a dudas, la identificación de cuál de las partes llevaba a cabo la prestación característica del contrato. Tres tendencias prevalecieron. La primera exponía que la prestación característica del contrato de franquicia la llevaba a cabo el franquiciador; la segunda entendía que dicha prestación era perfeccionada por el franquiciado, y la tercera consideraba que el contrato de franquicia no tenía un prestador que caracterizara este tipo contractual (De Miguel, 2000. p. 304). En las siguientes líneas abordaremos cada una de ellas.

\subsection{La prestación característica la llevaba a cabo el franquiciador}

Esta primera interpretación acerca de la parte que llevaba a cabo la prestación característica en el contrato de franquicia, se decantaba por reconocer que dicha prestación la realizaba el franquiciador. Por lo tanto, y de acuerdo al Art. 4.2 Convenio de Roma de 1980 sería la Ley de su residencia habitual la que regularía el contrato. Esta posición iba en consonancia con el Código Federal de Derecho internacional privado Suizo, en lo referente a la regulación de los Derechos de propiedad intelectual. Su Art. 122 establece lo siguiente: “Contracts concerning 
intellectual property rights shall be governed by the law of the State in which the party transferring the intellectual property right or granting the use thereof has his place of habitual residence".

El principal argumento para defender esta postura radicaba en las obligaciones llevadas a cabo por el franquiciador, puesto que se consideraba que estaban dotadas de una mayor complejidad ${ }^{5}$. Sobre todo, por el hecho de que el franquiciado básicamente reproduce lo que se le asigna como parte del modelo de franquicia, y satisface los pagos (royalties) (García, 2008, p. 235; García, 2010, p. 271). Asimismo, esta solución permitía que todos los contratos celebrados por el franquiciador fueran regidos por la misma Ley, lo que propiciaba una mayor certeza jurídica.

\subsection{La prestación característica la llevaba a cabo el franquiciado}

La segunda postura entendía que la prestación característica en el contrato de franquicia la llevaba a cabo el franquiciado. Quienes mantenían esta interpretación entendían que el franquiciado era quien asumía las obligaciones más importantes de la relación contractual, pues era quien, en última instancia, ponía en funcionamiento el negocio franquiciado asumiendo completamente, no solamente la carga económica, sino la responsabilidad del desarrollo del negocio ${ }^{6}$. Adicionalmente, se entendía que la residencia habitual del franquiciado normalmente coincidía con el lugar donde se adelantaba la labor comercial, y por ende, esta Ley sería la más previsible para las partes del contrato.

Por último, se consideraba que como buena parte de las soluciones judiciales designaban al distribuidor como el prestador característico en el contrato de distribución, al asimilarlo al contrato de franquicia, se consideraba que dicha solución era perfectamente aplicable a este contrato (García, 2008, p. 235).

\subsection{El contrato de franquicia no tenía prestador característico}

Esta última posición entendía que el contrato de franquicia no tenía un prestador característico, pues reconocía la imposibilidad de determinar cuál de las partes del contrato llevaba a cabo la obligación que caracterizaba la relación contractual, puesto que ambas partes ejecutaban prestaciones con alto grado de complejidad,

$5 \quad$ En este sentido: "my personal opinion is that the characteristic performance is effected by the franchisor, if only because this party is responsible for the most complex obligations". (García, 2008, p. 238).

6 En este sentido: "In my personal opinion, as with license contracts, due to the "reasonable settlement of the respective relationship", the law of the franchisee could be considered as more relevant in this respect". (Pauknerova, 2001, p. 118). 
que no correspondían a un intercambio simple de bienes y servicios por dinero ${ }^{7}$. Se rechazaba la teoría de la prestación característica para identificar la Ley aplicable al contrato de franquicia, porque -como se vio- este contrato contiene múltiples obligaciones recíprocas, todas ellas de alta complejidad que impiden establecer si el centro de gravedad del contrato se encuentra en el país de la sede del franquiciado o en el país del franquiciador, lo que explica por qué en la doctrina jurídica no existió uniformidad sobre quién era el prestador característico en el contrato de franquicia (Pellisé, 1999, p. 203) . Pues como lo expresa Carrascosa (2005) no "hay ningún motivo para inclinarse por el "conjunto de prestaciones" que debe proporcionar el franchisoro por el "conjunto de prestaciones" que debe proporcionar el franchisee". Ello es así porque el contrato no responde al esquema simple de intercambio de cosas o servicios por dinero".

Por tal motivo, se debe acudir a la regla de los vínculos más estrechos para que, de acuerdo al caso concreto, se analicen los diferentes puntos de conexión de la relación jurídica con los países intervinientes (García, 2008, p. 236).

En suma, los distintos tribunales acogieron alguna de estas tres tesis para determinar el prestador característico y así establecer la ley aplicable al contrato de franquicia, lo que se tradujo en inseguridad jurídica contractual en la Unión Europea, pues las partes no podían conocer previamente con alto grado de certeza la ley que regularía su contrato. Este problema se intentó solucionar con la transformación del Convenio de Roma a un Reglamento de la Unión Europea (Roma I). Se abordará ahora los cambios efectuados en dicho cuerpo jurídico para establecer la ley aplicable al contrato de franquicia.

\section{LA LEY APLICABLE AL CONTRATO DE FRANQUICIA EN EL REGLAMENTO ROMA}

\subsection{Consideraciones preliminares}

El Reglamento Roma I en su Art. 4.1 ha hecho una selección de contratos internacionales a los cuales a partir de ahora, se les designará su Ley aplicable de manera directa y rígida $^{8}$. El contrato de franquicia es uno de ellos. Efectivamente, el

7 En este sentido De Miguel Asencio, P.A. (2000) expone que no es "posible identificar la prestación característica del contrato de franquicia..." y por lo tanto debe acudirse a la regla de los vínculos más estrechos, donde la sede del franquiciador en muchos casos es la que tiene vínculos más estrechos con el contrato.

8 El Artículo 4.1 del Reglamento Roma I reza de la siguiente manera: Ley aplicable a falta de elección A falta de elección realizada de conformidad con lo dispuesto en el Artículo 3, y sin perjuicio de lo dispuesto en los Artículos 5 a 8, la ley aplicable al contrato se determinará de este modo: a) el contrato de compraventa de mercaderías se regirá por la ley del país donde el vendedor tenga su residencia habitual; b) el contrato de prestación de servicios se regirá por la ley del país donde el prestador del servicio tenga su residencia habitual; c) el contrato que tenga por objeto un derecho real inmobiliario o el arrendamiento de un bien inmueble se regirá por la ley del país donde esté 
Art. 4.1e determina que "el contrato de franquicia se regirá por la Ley del país donde el franquiciado tenga su residencia habitual"".

Esta regla rígida contenida en el Art. 4.1e Reglamento Roma I sobre el contrato de franquicia, resuelve una gran controversia mantenida bajo la vigencia del Convenio de Roma de 1980, en orden a determinar la prestación característica en este contrato (Magnus, 2009, p. 41). Así, en el Reglamento Roma I no existe la necesidad de establecer cuál de las partes lleva a cabo la prestación característica del contrato, pues el operador jurídico directamente deberá aplicar a la relación contractual, la Ley de la residencia habitual del franquiciado, con lo cual, se garantiza la previsibilidad y certeza del resultado, favoreciendo, como es lógico, la seguridad jurídica de la Unión Europea (Rauscher, 2011, p. 220). El considerando 17 del Reglamento Roma I expone que el contrato de franquicia es un contrato de servicios. Sin embargo, a pesar de reconocer esta realidad, el legislador de la Unión Europea ha considerado oportuno otorgar una regulación específica para esta clase de contratos en el Art. 4.1e. Por esta razón, a los contratos de franquicia no le será aplicable la regla rígida establecida en el Art. 4.1b (prestación de servicios).

Una de las razones para establecer como regla especial que el contrato de franquicia se rija por la Ley de la residencia habitual del franquiciado, puede ser, como lo expone L. García, (2008) que en lugar de buscar la prestación característica del contrato, el legislador le otorgó mayor importancia a otros elementos de la relación jurídica (p. 237). Esto significa, que el legislador de la Unión Europea, al designar la Ley del franquiciado como reguladora de las relaciones jurídicas entre las partes, no está reconociendo que la prestación característica en este contrato sea la llevada a cabo por el franquiciado ${ }^{10}$. Lo que sí hace, es otorgar protección a la

sito el bien inmueble; d) no obstante lo dispuesto en de la letra c), el arrendamiento de un bien inmueble celebrado con fines de uso personal temporal para un período máximo de seis meses consecutivos se regirá por la ley del país donde el propietario tenga su residencia habitual, siempre que el arrendatario sea una persona física y tenga su residencia habitual en ese mismo país; e) el contrato de franquicia se regirá por la ley del país donde el franquiciado tenga su residencia habitual; f) el contrato de distribución se regirá por la ley del país donde el distribuidor tenga su residencia habitual; g) el contrato de venta de bienes mediante subasta se regirá por la ley del país donde tenga lugar la subasta, si dicho lugar puede determinarse; h) el contrato celebrado en un sistema multilateral que reúna o permita reunir, según normas no discrecionales y regidas por una única ley, los diversos intereses de compra y de venta sobre instrumentos financieros de múltiples terceros, tal como estipula el Artículo 4, apartado 1, punto 17, de la Directiva 2004/39/CE, se regirá por dicha ley.

9 Art. 4.1e del Reglamento (CE) No. 593/2008 del Parlamento Europeo y del Consejo, de 17 de junio de 2008, sobre la ley aplicable a las obligaciones contractuales (Roma I), DOUE L 177 de 4 julio 2008, p. 6 .

10 No obstante, existen autores que reconocen que el legislador de la UE ha expresado su opinión acerca quien lleva a cabo la prestación característica del contrato de franquicia. Vid. "Now it is clear that the franchisee has to be regarded as the characteristically performing party, and regularly the law at the franchisee's seat applies". Magnus, U. (2009) "Article 4 Rome I Regulation: The Applicable Law in the Absence of Choice", en F. Ferrari/ S. Leible, Rome I Regulation: The Law Applicable to Contractual Obligations in Europe, (pp. 27-50,). Sellier. European Law Publishers, Munich, concr. p. 41. 
parte que considera más débil en la relación comercial, el franquiciado, pues la Ley de su residencia habitual será la reguladora del contrato (Rauscher, 2011, p. 220). Sin embargo, este no es un argumento válido para decantarse por la ley de la residencia habitual del franquiciado, pues las dos partes son empresarios que participan en el comercio internacional asumiendo los mismos riesgos. En consecuencia, este argumento esgrimido por el legislador de la Unión Europea no está acorde con la realidad comercial (Plender y Wilderspin, 2009, p. 182).

Adicionalmente, parece ser que el legislador de la Unión Europea ha querido establecer esta regla rígida para favorecer la aplicación de la Ley del "mercado afectado por la franquicia", ya que en la mayoría de casos el lugar de la sede del franquiciado y el lugar donde se explota el negocio franquiciado, son el mismo (García, 2010, p. 272).

La doctrina ha considerado acertada la regulación específica para los contratos de franquicia -posición que debe compartirse-, ya que este contrato presenta una particular estructura, dotada de un alto grado de complejidad, lo que dificulta establecer el centro de gravedad de la operación. Adicionalmente, con esta regla rígida se pretende subsanar los distintos problemas presentados en el Convenio de Roma de 1980, buscando alcanzar un alto grado de previsibilidad de la Ley aplicable al contrato de franquicia (García, 2008, p. 238).

\subsection{Relaciones jurídicas cubiertas por el Art. 4.1e Reglamento Roma I}

El Reglamento Roma I no proporciona una definición de contrato de franquicia, ni especifica las relaciones jurídicas enmarcadas en el Art. 4.1e. Por lo tanto, se debe entender que este precepto cubre cualquier tipo de contrato de franquicia. Sin embargo, existen autores que dudan de si los contratos de Máster Franquicia pueden estar incluidos en la regulación del Art. 4.1e Reglamento Roma I, pues no constituyen una franquicia directa. Si se acepta esta postura, se debería acudir al apartado segundo del Art. 4, y utilizar la prestación característica para determinar la Ley aplicable. Como es imposible establecer el prestador característico, se concluye que ha de acudirse al Art. 4.4 Reglamento Roma I y buscar los vínculos más estrechos del contrato (García, 2010, p. 279).

No obstante, la correcta interpretación del precepto debe incluir al contrato de Máster franquicia para que sea regulado por el Art. 4.1e, ya que se debe incluir a todo tipo de franquicias, sin entrar en consideración del nivel de integración y dependencia o la libertad del franquiciado (Magnus, 2009, p. 41)

De acuerdo a lo anterior, las relaciones jurídicas cubiertas por el Art. 4.1e son las siguientes: 


\subsubsection{Franquicia de producción.}

En este tipo de franquicia, el franquiciado es quien fabrica directamente los productos mediante las instrucciones, y en algunos casos, con los materiales que le proporciona el franquiciador, y que posteriormente vende con la misma marca de éste (Calvo y Carrascosa, 2011; Duran, 2006).

\subsubsection{Franquicia de distribución.}

El TJUE define esta clase de franquicias como aquel contrato donde "una empresa, instalada en un mercado como distribuidor y que haya podido elaborar así un conjunto de métodos comerciales, concede, mediante una retribución, a comerciantes independientes, la posibilidad de establecerse en otros mercados utilizando su rótulo y los métodos comerciales, que le han garantizado el éxito"11.

En definitiva, más que una clase de distribución comercial, es una forma de aplicar unos conocimientos previamente adquiridos, para abarcar una mayor porción del mercado, sin hacer una elevada inversión. Este contrato, presenta rasgos similares al contrato de distribución, puesto que el objetivo final de ambas relaciones jurídicas es lograr la reventa de los productos del fabricante, mediante la intervención independiente y por cuenta propia de un tercero. Sin embargo, el punto clave de distinción se encuentra en que en la franquicia de distribución, no solo se entregan mercancías, sino todo un modelo de negocio, es decir, una fórmula empresarial compleja. Esto implica -como se ha anotado antes- la transmisión del know-how, el uso de la marca y sellos distintivos etc. (Broseta y Martínez, 2011, p. 135).

\subsubsection{Franquicia de servicios.}

En este tipo de franquicia, el franquiciado ofrece un determinado servicio que desarrolla mediante la fórmula que le transmite el franquiciador, "utilizando el rótulo y el nombre comercial, e incluso la marca del cedente"12. El franquiciador, adicionalmente, tiene la obligación de transmitir todos los secretos del negocio a sus franquiciados (Burgos y Fernández, 2010, p. 428). Su contenido es muy cercano al de la franquicia de distribución, pero aquí el objeto no es la comercialización de productos, sino la prestación de servicios (Guardiona, 1998, p. 244).

\subsubsection{Franquicia Máster o principal.}

Es aquella franquicia, que dentro de un territorio determinado, el franquiciador otorga al franquiciado "en contraprestación de una de una compensación financiera

11 STJCE 1986\34 Pronuptia de París GmbH, Frankfurt am Main vs Pronuptia de París IrmgardScinllgalisHamburg.

12 STJCE 1986\34 Pronuptia de París GmbH, Frankfurt am Main vs Pronuptia de París IrmgardScinllgalisHamburg. 
directa, indirecta o ambas", el Derecho de explotación de la franquicia, pudiendo éste captar franquiciados para el cumplimiento del contrato (A.P., 2009; Burgos y Fernández 2010; Calvo y Carrascosa, 2011). Ésta es la que se conoce como franquicia indirecta, donde el franquiciado tiene la posibilidad de subcontratar a otros franquiciados, y como en este contrato el franquiciado principal actúa como franquiciador, no existiría -en principio- vínculo contractual entre el fabricante y el franquiciado final (Guardiona, 1998, Brosetay Martínez, 2011).

\subsubsection{Franquicia Corner.}

Esta modalidad de franquicia viene dada en función del lugar mismo donde se desarrolla el negocio franquiciado (Guardiona, 1998, p. 245). Dichas franquicias tienen la particularidad de desarrollarse al interior de otro establecimiento comercial, llevando a cabo sus técnicas y procedimientos comerciales de forma independiente y autónoma, al establecimiento donde se ubica (Burgos y Fernández, 2010, p. 47). La dependencia económica se puede dar en función del espacio ocupado por el corner, o por medio de un porcentaje sobre las ventas (Chuliay Beltrán, 1992, p. 167).

\section{CONCLUSIONES}

La determinación de la ley aplicable al contrato de franquicia de manera rígida por medio del Art. 4.1e, pone fin a la discusión sobre la aplicación de la teoría de la prestación característica a esta relación contractual, y constituye una disposición con un alto nivel de previsibilidad para los contratantes. La identificación de la Ley aplicable a los contratos de franquicia en el Convenio de Roma de 1980 presentó grandes dificultades, principalmente porque es un contrato donde existe un equilibrio de prestaciones llevadas a cabo por los contratantes, y esto dificultó el establecimiento del centro de gravedad, a fin de establecer la prestación característica del contrato. Por tal motivo, existió una heterogénea interpretación de la forma de aplicar la teoría de la prestación característica a este contrato, donde tres tendencias prevalecieron. La primera de ellas, entendía que la prestación característica en el contrato de franquicia la llevaba a cabo el franquiciador, la segunda, consideraba que el prestador característico era el franquiciado, y por último, se consideraba que este contrato no tenía un prestador característico.

El Reglamento Roma I ha solucionado este problema, al incorporar en su Art. 4.1e, una norma rígida que estipula que el contrato de franquicia será regido por la Ley de la residencia habitual del franquiciado. De esta manera, el operador jurídico ya no tendrá que establecer quién es el prestador característico, sino que aplicará de manera directa la regla contemplada en el precepto. Con esta elección, el legislador de la Unión Europea entiende que el franquiciado es la parte débil de la relación jurídica, y por ello, ha querido protegerlo designando la Ley de su residencia habitual como la reguladora del negocio jurídico. 
De esta manera, se solucionan los graves problemas de previsibilidad de la ley aplicable a los contratos de franquicia, y es una circunstancia que se debe valorar positivamente, pues la franquicia es una relación jurídica de gran éxito en el mundo empresarial, con un elevado nivel de crecimiento. Sin embargo, los contratantes se ven ahora avocados a otra incertidumbre: cuáles relaciones jurídicas están cubiertas por la regla del Art. 4.1e. Como el Reglamento Roma I no proporciona unas directrices en esta materia, se debe entender que se aplica a toda clase de franquicias sin considerar su grado de integración, dependencia o libertad del franquiciado. Esta interpretación es la correcta, y debe rechazarse aquella que pretende sólo aplicar este precepto a las relaciones directas entre franquiciado y franquiciador, dejando por fuera relaciones jurídicas como la Máster Franquicia.

En conclusión, se debe aplicar este precepto a los contratos de: franquicia de producción, franquicia de distribución, franquicia de servicios, Máster franquicia o franquicia principal y franquicia córner.

\section{REFERENCIAS}

Angulo Rodríguez, L. (2009). Colaboradores del empresario y otros contratos de colaboración, en G.J. Jiménez Sánchez (coord.), Derecho mercantil 2, 13ª ed., Barcelona: Ariel.

Baena Graciá, V. (2009). Teorías y líneas de investigación en el sistema de franquicia: una revisión desde los años 60 hasta 2009, en Cuadernos de Gestión, (2)10, 43 $-66$.

Bescos, M. (1993). Contratos internacionales. Manual práctico. Madrid: ESIC Editorial.

Burgos Pavon, M.S. y Fernández Iglesias, G. (2010). La Franquicia. Tratado práctico y jurídico, Madrid: Ediciones Pirámide.

Broseta Pont, M. y Martínez Sanz, F. (2011). Manual de Derecho mercantil. Vol. 2, Madrid: Tecnos.

Carrascosa González, J. (2004). Globalización y Derecho Internacional privado en el siglo XXI, Anales de Derecho. Universidad de Murcia, (22), 17 - 58.

Calvo Caravaca J. y Carrascosa González, A. L. (2011). Derecho Internacional Privado2, $12^{\mathrm{a}}$ ed., Granada: Comares.

VO, Rom II-VO, Sellier, München.

Chulia Vicent, E. y Beltran Alandete, T. (1992). Aspectos jurídicos de los contratos atípicos I, Barcelona: J.M. Bosh editor.

De Miguel Asensio, P. A. (2000). Contratos internacionales sobre propiedad industrial, $2^{\mathrm{a}}$ ed, Madrid: Civitas.

Domínguez García, M. A. (2006). El contrato de franquicia, en: Bercovitz RodríguezCano. A. (dir.), Contratos mercantiles, $2^{\mathrm{a}}$ ed., Navarra: Thomson Aranzadi. 
Duran Ayago, A. (2006). Contratos internacionales de distribución, en Calvo Caravaca, A.L. / Carrascosa González, J. (dir.), Curso de contratación internacional, $2^{\mathrm{a}}$ ed., Madrid: Colex.

Fentiman, R. (2010). International commercial litigation. Oxford: Oxford University Press.

Fuentes Camacho, V. (2001). Los contratos internacionales de franquicia y el DIPr: Una aproximación en clave de "acceso", en Anuario español de Derecho Internacional privado, Tomo I, 117 - 144. España: Universidad Complutense de Madrid.

Jiménez Sánchez, G. J. (2010). Lecciones de Derecho mercantil, 14 ed., Madrid: Tecnos.

García Gutiérrez, L. (2010). Los contratos de franquicia internacional, en Revista de Derecho Mercantil (275), 249 - 281.

Garcia Gutierrez, L. (2008). Franchise contracts and the Rome I Regulation on the law applicable to international contracts", Yearbook of Private International Law (10).

García Vázquez, S. (2000). La franquicia y el derecho de la competencia, en Ortíz Blanco, L. Y Sopeña Blanco, V., Derecho de la competencia europeo y español: curso de iniciación, Madrid: Universidad Rey Juan Carlos.

Guardiona, E. (1998). Contratos de colaboración en el comercio internacional, Bosh, Barcelona.

Guillen Larrea, M. V. (1995). El contrato de franquicia, Distribución y consumo (23), versión online.

Mayorga Toledano, M. C. (2007). El contrato mercantil de franquicia, $2^{\mathrm{a}}$ ed, Granada: Comares.

Magnus, U. (2009). Article 4 Rome I Regulation: The Applicable Law in the Absence of Choice, en: Ferrari, F. / Leible, S., Rome I Regulation: The Law Applicable to Contractual Obligations in Europe, Sellier, Munich: European Law Publishers.

Pauknerova, M. (2001). Private international law in the Czech Republic. Netherlands: Wolters Kluwer.

Pellisé De Urquiza, C. (1999). Los contratos de distribución comercial. Problemas de Derecho Internacional privado de la Comunidad Europea, Barcelona: Bosch.

Pellisé De Urquiza, C. (1998). Los contratos de distribución comercial. Problemas de Derecho Internacional privado de la Comunidad Europea, Barcelona: Bosch.

Plender, R. yIlderspin, M. (2009). The European Private International Law of Obligations, $3^{\mathrm{a}}$ ed., London: Sweet \& Maxwell.

Rauscher, T. (2011). Europäischeszivilprozess- und kollisionsrechtEuZPR/EuIPR: kommentar: Rom I-VO, Rom II-VO, München: Sellier.

Rauscher, T. (2011). Europäischeszivilprozess- und kollisionsrechtEuZPR/EuIPR. kommentar: Rom I. 
Duran Ayago, A.(2006). Contratos internacionales de distribución, en Calvo Caravaca, A.L. y Carrascosa González, J. (dir.), Curso de contratación internacional, $2^{\mathrm{a}}$ ed., Madrid: Colex; Sap Álava de 10 abril de 2006;

Stjce $1986 \backslash 34$ Pronuptia de París GmbH, Frankfurt am Main vs Pronuptia de París Irmgard Scinllgalis Hamburg.

Vega Penichet, L. (1988). El contrato de franquicia de distribución en la Comunidad Económica Europea: análisis desde la perspectiva de la libre competencia, en Revista de estudios e investigación de las Comunidades Europeas (5), mayoseptiembre, 265 - 291. 